\title{
The Optimal Felling Rate in the Palm Oil Plantation System
}

\author{
${ }^{1}$ Mohd Ismail Abd Aziz*, ${ }^{2}$ Noryanti Nasir and ${ }^{3}$ Akbar Banitalebi \\ 1,2 Department of Mathematical Sciences, Faculty of Science \\ Universiti Teknologi Malaysia, 81310 Johor Bahru, Malaysia \\ ${ }^{3}$ UTM Center for Industrial and Applied Mathematics \\ Universiti Teknologi Malaysia, 81310 Johor Bahru, Malaysia \\ ${ }^{*}$ Corresponding author: mismail@utm.my
}

Article history

Received: 21 November 2017

Received in revised form: 14 January 2018

Accepted: 1 March 2018

Published on line: 1 April 2019

\begin{abstract}
Successful oil palm plantation should have high profit, clean and environmental friendly. Since oil palm trees have a long life and it takes years to be fully grown, controlling the felling rate of the oil palm trees is a fundamental challenge. It needs to be addressed in order to maximize oil production. However, a good arrangement of the felling of the oil palm trees may also affect the amount of carbon absorption. The objective of this study is to develop an optimal felling model of the oil palm plantation system taking into account both oil production and carbon absorption. The model facilitates in providing the optimal control of felling rate that results in maximizing both oil production and carbon absorption. With this aim, the model is formulated considering oil palm biomass, carbon absorption rate, oil production rate and the average prices of carbon and oil palm. A set of real data is used to estimate the parameters of the model and numerical simulation is conducted to highlight the application of the proposed model. The resulting parameter estimation that leads to an optimal control of felling rate problem is solved.
\end{abstract}

Keywords Carbon absorption; optimal felling rate model; system equation

Mathematics Subject Classification 93A30, 97M10

\section{Introduction}

Elaaeis guinensis or oil palm trees known as one of the most influential plantation has various advantages. It produces oil, use as renewable energy, helps in improving people life and a contributor to the national economy [1]. A part from producing good oil, carbon absorption increases the value of palm oil plantation that ultimately contributes to nation's profit and clean environment [2-3]. However, felling and replacement of oil palm trees affect the amount of oil and carbon absorption [4].

A continuous palm oil production will ensure that the increases in oil demand are met [5]. However, the yield of palm oil and the rate of carbons absorption depends on the growth 
or age of oil palm tree [6-8]. In the first 2 to 3 years the young palm is only contributing a small yield because the plant is not fully grown but still contributes in absorbing carbon. Similarly, when the tree is old, the yield rate and carbon absorption are also low. The old trees should be replaced as the palms are too tall for efficient harvesting and constant in sequestering carbon [9-10].

Restricted expansion of oil palm plantation area due to deforestation and reservations is another challenge [11]. Even though land expansion is restricted, felling old palm trees and replanting new palm trees will continue to sequester carbon [12]. Basiron [13] recommended that $5 \%$ of the Malaysian oil palm area should be replanted each year, both to upgrade the quality of the plantations and to help support the price of the palm oil. However, the replanting and felling procedure causes a loss of Fresh Fruit Bunch as cash cost [14] and less carbon absorption rate [15]. Some suggested for earlier replanting such that it will yield more heavily but there is little evidence for the rising yield profile to support this [7], 14].

A comprehensive model on the optimal control of tree biomass is considered by Chaudary et al. [16], they proposed an aged-structured forestry biomass to define the premature and mature trees. A forest system through a suitable number of state variables is described by Garcia-Franco et al. [17] to model the rate of change in forest growth . Nasir et al. [18] develop a time-invariant linear quadratic optimal control model for controlling the felling and harvest rate of the oil palm plantation. The results provide an optimal feedback control for the felling and harvest rates. Banitalebi et al. [15] and Gaoue et al. [19] both applied a system of delay differential equation model to describe the behavior of oil palm and non-timber forest biomass respectively.

Other models that shown variability on pre-21]. On the other hand, the advantages of oil palm in sequestering carbon are discussed statistically in [2-3], [12], [22-24]. Amelia et al. [25] considered fuzzy expert system model to illustrate the amount of Crude Palm Oil losses while Dumrongsiri [10] used mixed integer linear programming as decision tools in finding optimal result in production and logistic. In 2002, Ismail and Mamat [7] applied deterministic model to study the optimal age in replanting the palm oil trees. With regards, only a few optimal control models were discussed in oil palm plantation taking into account both oil and carbon absorption [16], [26].

The aim of this study is to develop an optimal felling rate model of the palm oil plantation taking into account both oil production and carbon absorption. The model facilitates in providing the optimal control of felling rate that results in maximizing both oil production and carbon absorption. With this model, the decision on how many old trees must be felled in a certain period of time can be decided earlier. The model is formulated considering young oil palm trees, mature oil palm trees, carbon absorption rate and palm oil production rate. This study assumed that the felling rate can be controlled. The felling rate is obtained through solving the optimal control model of the oil palm plantation system. A set of real data is used to estimate the parameters of the model.

The remaining of this paper is organized as follows. In Section 2, a mathematical model is proposed to explain the behaviour of young and mature oil palm trees. The numerical simulation is conducted in Section 3 to highlight the application of the proposed model. The control problem is then solved and the result is discussed in Section 4. Finally the conclusion is given in Section 5. 


\section{The Mathematical Model}

A model is presented to study the behaviour of palm trees in producing oil and helps in absorbing carbon. The trees are categorized into two parts namely, the young or immature trees $Y(t)$ and the mature trees $P(t)$. The model is best described by the following equations.

$$
\begin{aligned}
& \dot{Y}(t)=r Y(t)\left(1-\frac{Y(t)}{k}\right)-\eta Y(t)+f(t) P(t) \\
& \dot{P}(t)=\eta Y(t)-f(t) P(t)-m P(t)
\end{aligned}
$$

In this model, it is assumed that the felling rate, define as $f(t)$ can be controlled. The process of felling the oil palm trees is followed by the process of replanting the new oil palm trees. The total of the new oil palm trees depend on how many trees are felled. This means that the process of replanting the new oil palm trees is equal to felling the old and insufficient oil palm trees. Thus the new plantation rate in equation (1), defined as $+f(t) P(t)$ is the same as felling rate in equation (2) defines as $-f(t) P(t)$. The immature or young trees in equation (1) grow logistically with fixed growth rate $r$ and $k$ denotes as the carrying capacity.

The rate of felling insufficient trees can be controlled as indicates in equation (2). The transition rate from young or immature to mature palm oil trees is defined by $\eta$, and $m$ is the natural depletion rate of mature oil palm trees. The state variables are $Y(t)$ and $P(t)$ respectively, while the felling rate $f(t)$ is the control variable.

$$
\begin{aligned}
& C(t)=\alpha(Y(t)+P(t)) \\
& O(t)=\gamma h P(t)
\end{aligned}
$$

Generally, carbon absorption of natural plantation depends on the growth of plantation [27]. This implies that the amount of carbon in oil palm trees can be accumulated by the proportional amount of oil palm trees with different scale, described in equation (3). It is further assumed that in equation (4) the oil production is directly proportional to the mature trees of palm oil plantation. The weighted of carbon absorption and the rate of oil production are $\alpha$ and $\gamma$ respectively while $h$ indicates the harvest rate. The discussed parameters and variables are given in Table 1 and 2 respectively.

With the intention to estimate suitable values for the parameters of the model, a set of oil palm plantation data was collected from Malaysian Palm Oil Council (MPOC) and Malaysian Palm Oil Board (MPOB). This data consist of variables listed in Table 2. The data has been collected by sampling from the area of Peninsular Malaysia and measured in tonnes per hectare per year while for carbon in kilograms per hectare per year. While, the carbon absorption rate is taken from the literature [12]. As the rate of felling $f(t)$ is assumed to be controllable, the optimal value is obtained through solving the optimal control model of oil palm plantation system. The process is presented in the third and fourth sections.

\section{Simulation}

Ideally to suit the model with the oil palm problem, numerical simulation is considered. The simulation is conducted to check the system of equation (1)-(4) dynamics by using the control parameterization. This is a popular numerical technique for solving optimal control problems 
Table 1: Description of Parameters

\begin{tabular}{|c|l|}
\hline Parameter & \multicolumn{1}{|c|}{ Description } \\
\hline$r$ & The intrinsic growth rate of the young / immature \\
\hline$k$ & The carrying capacity \\
\hline$\eta$ & The transition rate from young / immature to mature palm oil tree \\
\hline$d$ & The natural depletion rate of mature palm oil \\
\hline$\gamma$ & The rate of oil production \\
\hline$\alpha$ & The rate of carbon absorption \\
\hline$h$ & The harvest rate \\
\hline
\end{tabular}

Table 2: Description of Variables

\begin{tabular}{|c|c|}
\hline Variables & Description \\
\hline$f(t)$ & The felling rate of mature palm oil \\
\hline$C(t)$ & The amount of carbon \\
\hline$O(t)$ & The amount of produce oil \\
\hline$P(t)$ & The mature palm oil tree \\
\hline$Y(t)$ & The young / immature palm oil tree \\
\hline
\end{tabular}

[28-29]. The main idea of control parameterization is to discretize the control space by approximating the control function. In this study, the control variable is parameterized as follows:

$$
f(t)=\sum_{i=1}^{m} f_{i} x_{\left[t_{i}, t_{i+1}\right]}(t)
$$

where $x$ is the indicator function such that,

$$
x(t)_{\left[t_{i}, t_{i+1}\right]}=\left\{\begin{array}{l}
1, t \in\left[t_{i}, t_{i+1}\right] \\
0, \text { otherwise }
\end{array}\right.
$$

for subinterval $i=1,2,3, \ldots . m$. The cost function of this control problem can be stated as follows:

$$
\max \int_{t_{0}}^{t_{f}}\left(w_{1} O(t)^{2}+w_{2} C(t)^{2}\right) d t
$$

The initial and final time are represented by $t_{0}$ and $t_{f}$ respectively. While $w_{1}$ and $w_{2}$ are weight parameters for carbon absorption and oil production respectively. To obtain a solution of maximizing the amount of oil and carbon, first the study finds the optimum value of $f(t)$ through simulation process using control parameterization techniques. The optimal value of $f(t)$ is then substituted into the model and the solution of the resulting ODE provides the results as depicted in the result and discussion section. 


\subsection{Validity of the Model}

To ensure the validity of the proposed model, a stability analysis is established. For simplification of equation (1), the carrying capacity is denoted by $k=\frac{r}{b}$, new plantation is denoted as $\eta$ and the transition rate from young to mature palm oil tree is denoted as $c$ thus

$$
\dot{Y}(t)=r Y(t)\left(1-\frac{Y(t)}{k}\right)-c Y(t)+n P(t)
$$

At the long-term scale, it is assumed that the dynamics of $P$ are at a quasi steady state in which $\frac{d P}{d t}=0$ thus $P=\frac{c Y}{f-m}$. Simplifying equation (5) and $P=\frac{c Y}{f-m}$ into a single equation become

$$
\frac{d Y}{d t}=r Y-\frac{r Y^{2}}{K}-c Y+\frac{c n Y}{f-m}
$$

The equilibrium points are identified by finding all values of $Y$ (when $\frac{d Y}{d t}=0$ ). The two equilibrium points are $Y=0$ and $Y=\left[\frac{r}{b^{2}}-\frac{c}{b^{2}}\left[1-\left(\frac{n}{f-m}\right)\right]\right]$. To examine the stability of the equilibrium points, consider a small perturbation around point $Y(t)=Y^{*}+\varepsilon(t)$ where $\varepsilon$ is a first order small quantity, $\frac{d \varepsilon}{d t}=\frac{d}{d t}\left(Y-Y^{*}\right)$ such that $\frac{d Y}{d t}=f\left(Y^{*}+\varepsilon\right)$. Performing Taylor series expansion on $\frac{d Y}{d t}$ and assumed that the higher terms are negligible, thus the approximate equation is $f\left(Y^{*}+\varepsilon\right)=\left.\varepsilon \frac{d f}{d t}\right|_{Y=Y^{*}}$, and substitute it into $\frac{d \varepsilon}{d t}$, obtained solution of $\varepsilon=\varepsilon_{0} e^{(r-c) t}$ and $\varepsilon=\varepsilon_{0} e^{\left(r-\left(\left[\frac{2 r}{b}-\frac{2 c}{b}\left[1-\left(\frac{n}{f-m}\right)\right]\right]-c\right) t\right.}$ respectively. The result and discussion is presented in the fourth sections.

\section{Result and Discussion}

Generally oil yield and carbon absorption depends on the growth of young trees and felling of mature trees. Figure 1 shows the graph of the optimal control of felling rate $f(t)$ for times up to 100 years. The felling rate is simulated by parameterized the control variables towards approximating the control function. As a result, Figure 1 shows that a felling rate before the first 20 years is uncontrolled and it is almost fixed after 30 years.

The optimal state variable is achieved after applying optimal control to the system as described by equations (1) and (2). As illustrated in Figure 2, the amount of oil increases with a controlled felling rate. However if no control is applied, the state of oil is maintained at the lower level. Therefore a maximal oil yield is hard to be achieved.

Additionally, based on equation (3) the amount of carbon absorption is proportional to the amount of young and mature trees. Result has shown that the amounts of carbon absorption increases with optimal controlled felling of palm trees as depicted in Figure 3. Although oil and carbon depend on $f(t)$, the results of Figure 2 and 3 are not in the similar shape. It is due to $f(t)$ is changing over time and the effect of controlling felling rate $f(t)$, shows increasing progress on the amount of oil produces and the amount of carbon absorbed over time.

Plotting $Y(t)$ as a function of time, the graph of small perturbation of the equilibrium point illustrated in Figure 4 shows that $Y$ is approaching capacity $k$. The equilibrium point is stable if small perturbation decays exponentially [30]. Based on Figure 4, the equilibrium point $Y=\left[\frac{2 r}{b}-\frac{2 c}{b}\left[1-\left(\frac{n}{f-m}\right)\right]\right]$ is stable as $\varepsilon(t)$ decays exponentially. In real situation, besides felling and harvest activity the fluctuation of yield is associated with distruption of Geoderma, Termites and natural weather environment, however this study disregard these problems as, 


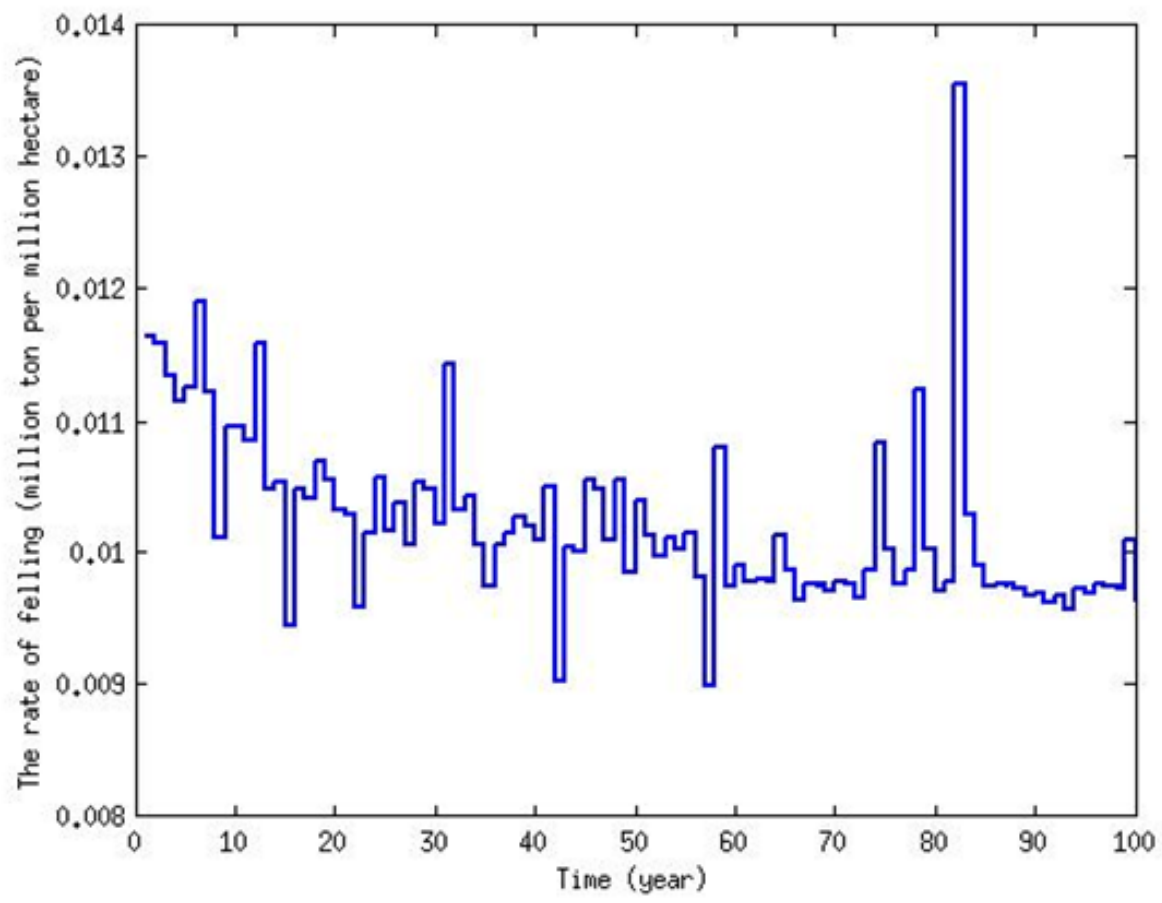

Figure 1: The Rate of Felling $f(t)$

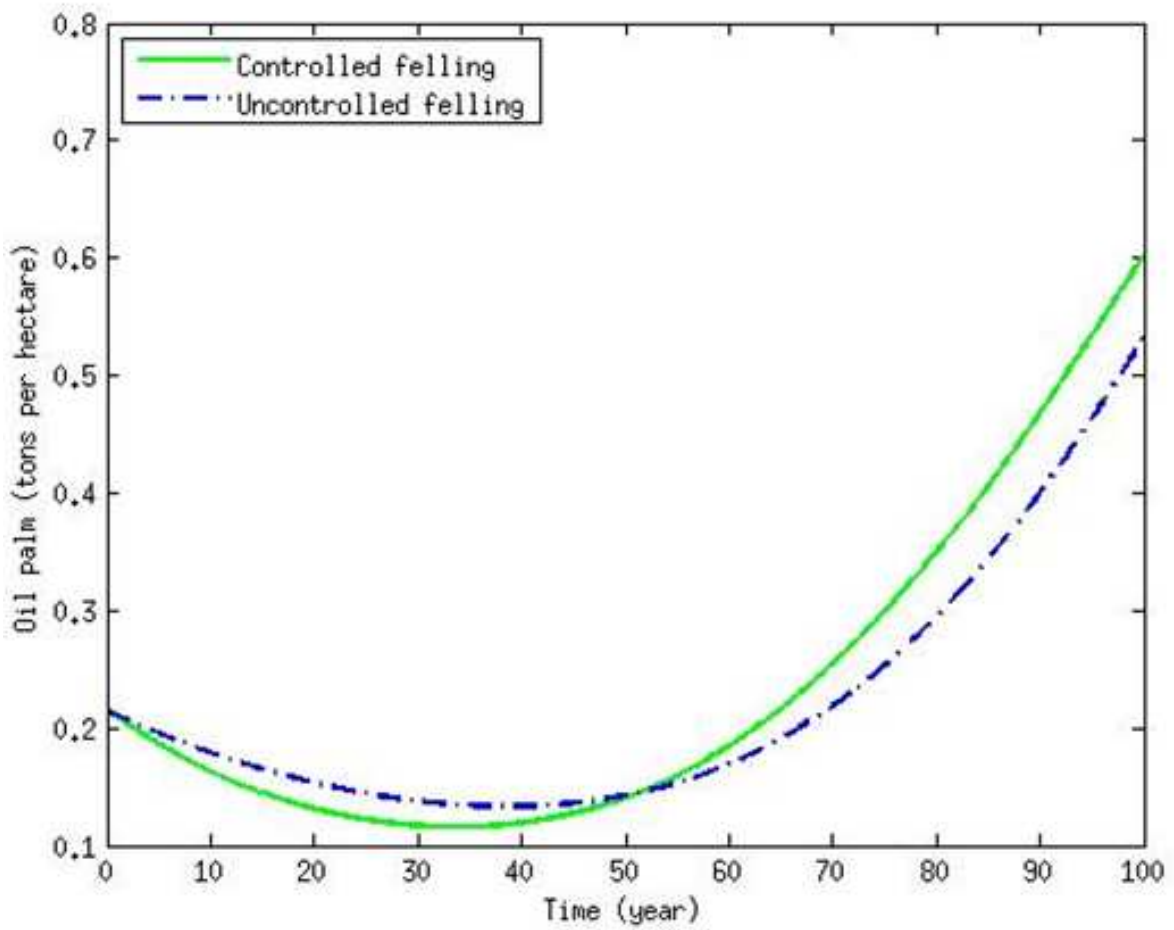

Figure 2: The Palm Oil with and without Control 


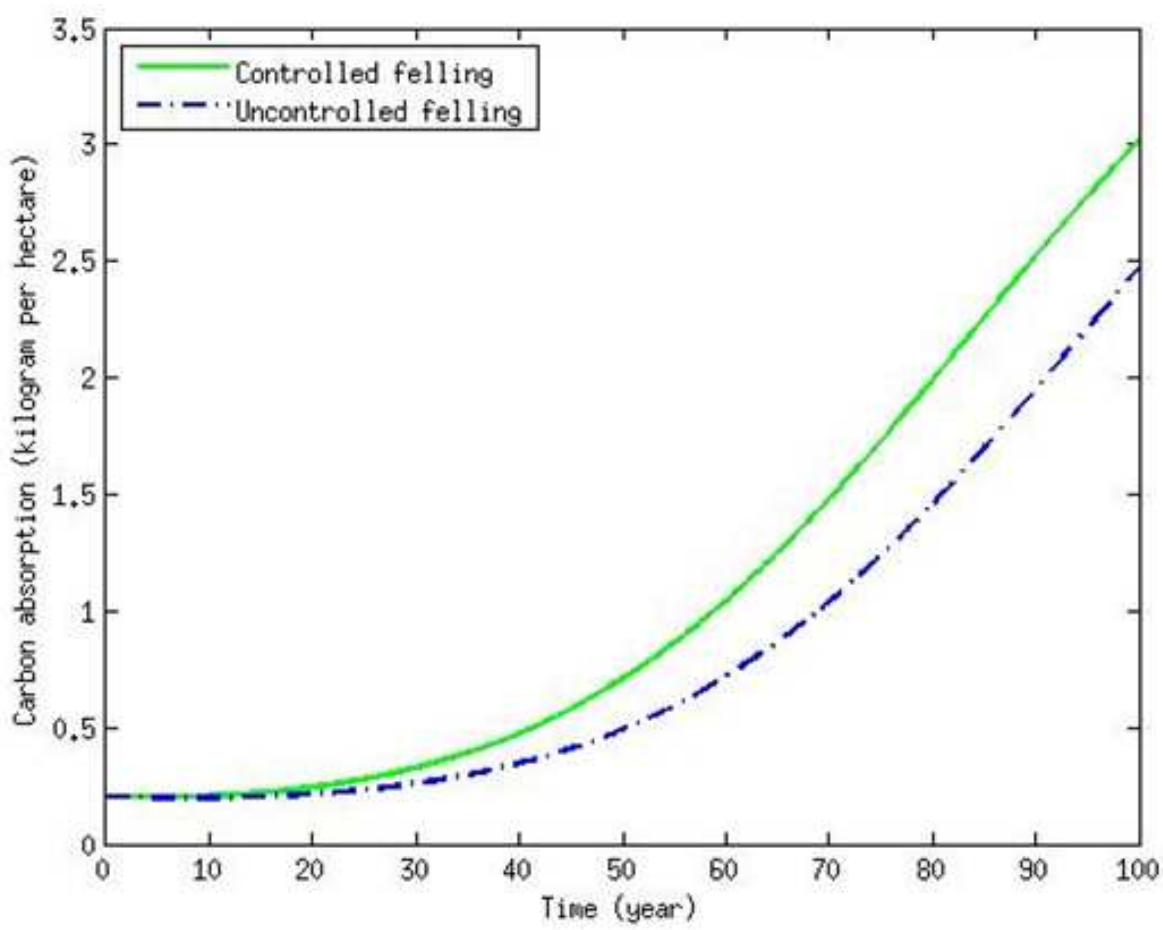

Figure 3: The Carbon Absorption with and without Control

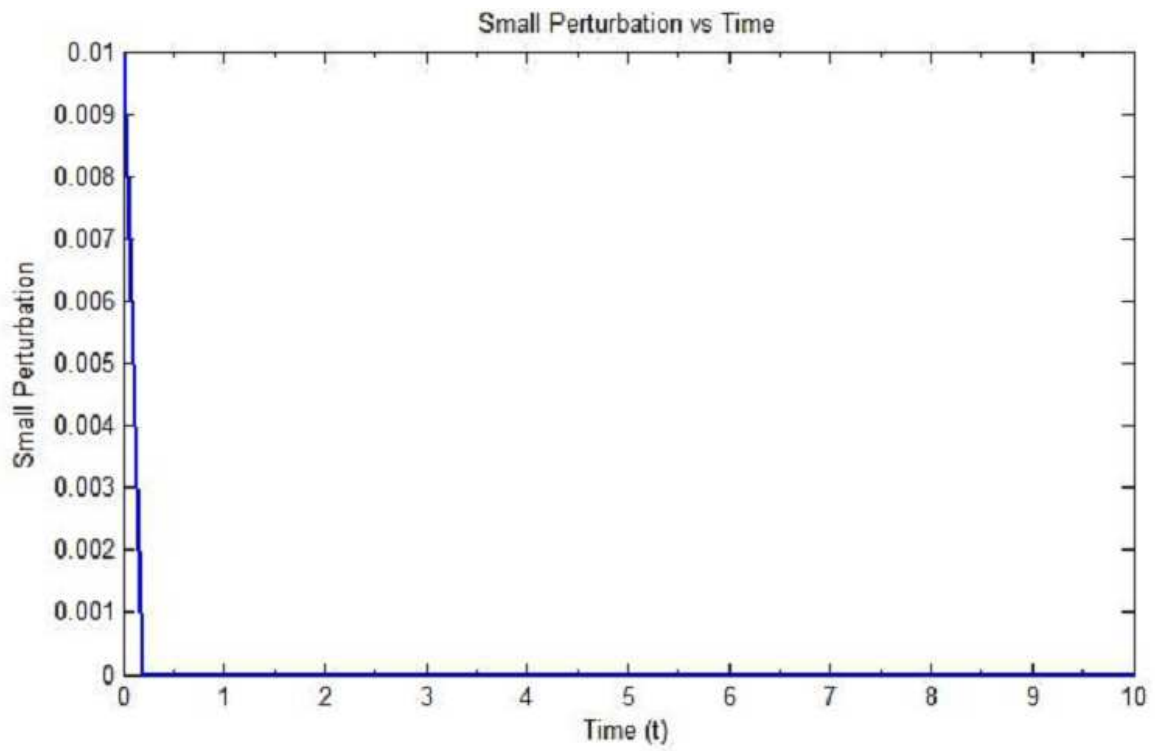

Figure 4: Graph of Small Perturbation of the Equilibrium Point 
the implication of this disruption can be controlled by the effective strategy of termites control and fertilizer treatments [31].

\section{Conclusion}

This article presents an optimal control felling rate model of young and mature oil palm trees in absorbing carbon and producing oil. The parameters of the model were estimated using real data. By considering felling rate as the control variable, the optimal state variable of oil and carbon are achieved. The amount of palm oil and carbon absorption increases with the controlled felling rate. The result of this study can be helpful for palm oil plantation management by controlling the felling rate to achieve both the maximum oil production and the maximum carbon absorption. By adding the value of carbon absorption, it helps to stimulate clean technology within palm oil plantation, thus in future bringing down emissions and drive palm oil investment to cleaner options.

\section{Acknowledgement}

This research is funded by Ministry of High Education Malaysia (MOHE) using STEM Grant with vote no. A. J091002.5600.07397. Authors would like to thank the reviewers for the thoughtful comments and constructive suggestions, which help to improve the quality of this manuscript.

\section{References}

[1] Sumathi, S., Chai, S. P. and Mohamed, A. R. Utilization of oil palm as a source of renewable energy in Malaysia. Renew. Sustain. Energy Rev. 2008. 12( 9): 2404-2421.

[2] Syahrinudin, The potential of oil palm and forest plantations for carbon sequestration on degraded land in Indonesia. Ecol. Dev. Ser. 2005. 28: 115.

[3] Pulhina, F. B., Lascob, R. D. and Urquiolab, J. P. Carbon Sequestration Potential of Oil Palm in Bohol, Philippines. Ecosyst. Dev. J. 2014. 4: 14-19.

[4] Patthanaissaranukool,W., Polprasert, C. and Englande, A. J. Potential reduction of carbon emissions from Crude Palm Oil production based on energy and carbon balances. Appl. Energy. 2013. 102: 710-717.

[5] Craven, C. The Honduran palm oil industry: Employing lessons from Malaysia in the search for economically and environmentally sustainable energy solutions. Energy Policy. 2011. 39(11): 6943-6950.

[6] Henson, I. E., Ruiz, R. and Romero, H. M. The greenhouse gas balance of the oil palm industry in Colombia: a preliminary analysis. I . Carbon sequestration and carbon offsets. Agron. Colomb. 2012. 30(3): 359-369.

[7] Ismail, A. and Mamat, M. N. The Optimal Age of Oil Palm Replanting. Oil Palm Ind. Econ. J. 2002. 2(1): 11-18. 
[8] Wahab, R., Samsi, H. and Mohamed, A. Utilization Potential of 30Year-old Oil Palm Trunks Laminated Veneer Lumbers for Non-structural Purposes. J. Sustain. Dev. 2008. $1(3)$.

[9] Corley, R. and Tinker, P. Growth, Flowering and Yield of Oil Palm. 4th Edition. Oxford. 2003.

[10] Dumrongsiri, A. Mathematical model for production, logistics and plant capacity planning of oil palm bunches. Igarss. 2014. 1: 1-5.

[11] Wilcove, D. S. and Koh, L. P. Addressing the threats to biodiversity from oil-palm agriculture. Biodivers. Conserv. 2010. 19(4): 999-1007.

[12] Kho L. K. and Jepsen, M. R. Carbon stock of oil palm plantations and tropical forests in Malaysia: a review. Singap. J. Trop. Geogr. 2015. 36: 249-266.

[13] Basiron, Y. Palm oil production through sustainable plantations. Eur. J. Lipid Sci. Technol. 2007. 109: 289-295.

[14] Corley, R. and Tinker, P. The Palm Oil. World Agric. Ser. 2003.

[15] Banitalebi, A., Aziz, M. I. A., Aziz, Z. A. and Nasir, N. Modelling and optimization for palm oil plantation management. Advances in Industrial and Applied Mathematics. 2016. 30046.

[16] Chaudhary, M., Dhar, J. and Prakash, O. A mathematical model for the conservation of forestry biomass with an alternative resource for industrialization: a modified Leslie Gower interaction. Model. Earth Syst. Environ. 2015. 1(4): 1-10.

[17] N. Garcia-Franco, M. Wiesmeier, M. Goberna, M. Martínez-Mena, and J. Albaladejo, "Carbon dynamics after afforestation of semiarid shrublands: Implications of site preparation techniques," For. Ecol. Manage. 2014. 319: 107-115.

[18] Nasir, N., Abd Aziz, M. I. and Banitalebi, A. Linear optimal control model for felling. Jurnal Teknologi. 2017. 1: 1-5.

[19] Gaoue, O. G., Jiang, J., Ding, W., Agusto, F. B. and Lenhart, S. Optimal harvesting strategies for timber and non-timber forest products in tropical ecosystems. Theor. Ecol. 2016. 9(3): 287-297.

[20] Kang, M. Z., Cournède, P. H., de Reffye, P., Auclair, D. and Hu, B. G. Analytical study of a stochastic plant growth model: Application to the GreenLab model. Math. Comput. Simul. 2008. 78(1): 57-75.

[21] Pallas, B., Soulié, J. and Aguilar, G. X-Palm, a functional structural plant model for analysing temporal, genotypic and inter-tree variability of oil palm growth and yield. Struct. Plant Model. 2013. 1-3.

[22] Suksuwan, S. Carbon assessment tool for new oil palm plantings. 2012. 1-38.

[23] Henson, I. E., Betitis, T. Tomda, Y. and Chase, L. D. C. The estimation of frond base biomass (FBB) of oil palm. J. Oil Palm Res. 2012. 24: 1473-1479.

[24] Lamade, E. and Bouillet, J. Carbon storage and global change: the role of oil palm. Oléagineux, corps gras, lipides. 2005. 7: 154-160.

[25] Amelia, L., Wahab, D. A. and Hassan, A. Modelling of palm oil production using fuzzy expert system. Expert Syst. Appl. 2009. 36(5): 8735-8749. 
[26] Gan, P. Y. and Li, Z. D. Econometric study on Malaysias palm oil position in the world market to 2035. Renew. Sustain. Energy Rev. 2014. 39: 740-747.

[27] Goetz, R., Hritonenko, N. and Mur, R. Forest Carbon Sequestration. 2013.

[28] Teo, K. L. A unified computational approach to optimal control problems. New York: Longman Scientific \& Technical. 1991.

[29] Lin, Q., Loxton, R. and Teo, K. L. The control parameterization method for nonlinear optimal control: a survey. J. Ind. Manag. Optim. 2013. 10(1): 275-309.

[30] Kumar, V. and Lal, S. Stability analysis of logistic growth model with immigration effect. Viskas Kumar. 2017. 16(1): 112-119.

[31] Sharma, M. Sustainability in the Cultivation of Oil Palm - Issues \& Prospects for the industry. J. Oil Palm Environ. An Off. Publ. Malaysian Palm Oil Counc. (MPOC). 2013. 4: $47-68$. 